\title{
Development of an Asymmetric Ultrafiltration Membrane from Naturally Occurring Kaolin Clays: Application for the Cuttlefish Effluents Treatment
}

\author{
Sonia Bouzid Rekik ${ }^{1-3 *}$, Jamel Bouaziz ${ }^{1}$, Andre Deratani ${ }^{2}$ and Semia Baklouti
}

${ }^{1}$ Laboratory of Industrial Chemistry, National School of Engineering, University of Sfax, BP 1173, 3038 Sfax, Tunisia

${ }^{2}$ Institut Européen des Membranes (IEM), Université Montpellier 2, Place E. Bataillon, 34095 Montpellier Cedex 5, France

${ }^{3}$ Laboratory of Materials Engineering and Environment, National School of Engineering, University of Sfax, BP 1173, 3038 Sfax, Tunisia

\begin{abstract}
This work concerns to the development and characterization of support and ultrafiltration membranes from naturally occurring- kaolin clays as principal components. The preparation and characterization of porous tubular supports, using kaolin powder with corn starch as poreforming agent, were reported. It has been found that the average pore size was about $1 \mu \mathrm{m}$ while the pore volume was $44 \%$ for supports sintered at $1150^{\circ} \mathrm{C}$ with a flexural strength of about $15 \mathrm{MPa}$. The deposition of the active layer was performed by slip casting method. The rheological study of various coatings with different concentration of kaolin powder, polyvinyl alcohol (PVA) and water under different conditions regarding temperature and stirring time was done. After drying at room temperature for $24 \mathrm{~h}$, the membrane was sintered at $650^{\circ} \mathrm{C}$. The average pore diameter of the active layer was $11 \mathrm{~nm}$ and the thickness was around $9 \mu \mathrm{m}$. The determination of the water permeability shows a value of $78 \mathrm{l} / \mathrm{h} . \mathrm{m}^{2}$.bar. This membrane can be used for crossflow ultrafiltration. The application of the cuttlefish effluent treatment shows an important decrease of turbidity, inferior to $1.5 \mathrm{NTU}$ and chemical organic demand (COD), retention rate of about $87 \%$. So, it seems that this membrane is suitable to use for wastewater treatment.
\end{abstract}

Keywords: Kaolin clays; Sintering; Ceramic supports; Ultrafiltration membrane; Cuttlefish effluent

\section{Introduction}

Membrane separation processes extend more and more every day in industrial uses, with new requirements concerning the materials and preparation procedures. Due to their potential application in a wide range of industrial processes such as water and effluent treatments [15], drink clarification [6,7], milk pasteurization [8-11], biochemical processing [12], inorganic membrane technology grows in importance.

The use of ceramic membranes has many advantages such as high thermal and chemical stability, pressure resistance, long lifetime, good resistance to fouling, and ease of cleaning [13-17]. The main process to prepare ceramic membranes includes first the obtaining of a good dispersion of small particles and then, the deposition of such dispersion on a support by a slip casting method.

Unfortunately, ceramic membrane fabrication, even though commercially available, still remains highly expensive from a technical and economic point of view due to the use of expensive powders such as alumina [18-22], zirconia, titania and silica [23,24]. To reduce the cost of ceramic membrane fabrication, recent research works are focused on the use of cheaper raw materials such as apatite powder [25], natural raw clay [26-29], graphite [30], phosphates [31,32], dolomite, kaolin [33-37] and waste materials such as fly ash [38-42].

To increase the reliability of the tenacity of these membranes having an asymmetric structure composed of at least two layers which are the support and the active layer, there is still a need for improvement in rheological properties of dip solution required for the preparation of active layer. The control of the rheological parameters of the dip solution is of significant importance for optimizing the final composition of the suspension. Indeed, the rheological properties depend on the physico-chemical characteristics of the raw material used and on the conditions under which the dip solution was prepared. Besides, the active layer thickness and microstructure of the membrane are mainly controlled by the viscosity of the dip solution which depends mainly on the particle size, the nature of the raw material, the addition of polymer and on temperature $[43,44]$.

The properties of the kaolin suspensions in water are largely modified by the presence of polymers. Many studies reported in the literature, treated as subject the rheological behavior of systems like "water- apatite- additive" and "water-clay-additive" where the additives were often a polymer. Most of these studies were devoted to the colloidal and/or rheological properties of these suspensions and on the effect of polymeric additives in order to obtain the optimal composition of the suspension [45-47].

In order to decrease the membrane cost, the present work describes the preparation of both porous support and active layer based on naturally occurring- kaolin clays (chemical structure: $\mathrm{Al}_{2} \mathrm{O}_{3} \cdot 2 \mathrm{SiO}_{2} \cdot 2 \mathrm{H}_{2} \mathrm{O}$ $[48,49])$, to elaborate a new asymmetric ceramic ultrafiltration membrane. This membrane is fabricated in different steps.

The first step is the preparation of porous tubular ceramic support using kaolin clays. Corn starch powder was added as pore-forming agent to produce sufficient porosity with acceptable mechanical property. The properties of porous support were discussed as a function of sintering temperature in order to optimize the preparation conditions. Their structural and functional properties are determined by different techniques. The most important parameters used in the characterization

*Corresponding author: Sonia Bouzid Rekik, National School of Engineering University of Sfax, Sfax, Tunisia, Tel: +21698462720; E-mail: bouzidsonia@gmail.com

Received June 04, 2016; Accepted September 03, 2016; Published September 10, 2016

Citation: Rekik SB, Bouaziz J, Deratani A, Baklouti S (2016) Development of an Asymmetric Ultrafiltration Membrane from Naturally Occurring Kaolin Clays: Application for the Cuttlefish Effluents Treatment. J Membra Sci Technol 6: 159. doi:10.4172/2155-9589.1000159

Copyright: (C) 2016 Rekik SB, et al. This is an open-access article distributed under the terms of the Creative Commons Attribution License, which permits unrestricted use, distribution, and reproduction in any medium, provided the original author and source are credited. 
of these substrates are: surface and internal morphology, mean pore size, pore size distribution, porosity, mechanical and chemical stability.

The second step is the characterization of the rheological properties of a dip solution which will be used to elaborate an ultrafiltration membrane by deposition using slip casting process of the active layer supported by the kaolin support. The adhesion of the layer to the macroporous ceramic support is achieved by capillary suction. The thickness of the layer depends on the physico-chemical properties of medium, as well as the viscosity of the slip. The study reveals also that the thickness of the active membrane layer can be controlled by the percentage of the kaolin powder added to the suspension and the deposition time.

The last step of this work concerns the application of the ultrafiltration elaborated membrane to the treatment of cuttlefish conditioning wastewater. Figure 1 shows a schematic representation of the sequential steps of the support, active layer, and the procedure of asymmetric ceramic membrane preparation.

\section{Materials and Methods}

\section{Materials}

In this study, both the supports and membranes were prepared from clay. The clay used in the present study is a kaolin Codex (notes as $\mathrm{K}$ ), it was recommended by the L.P.M Cerina (Laboratoire des Plantes Medicinales, Tunisia). Corn starch powder was used as a pore former.

\section{Characterization of the kaolin powder}

The chemical composition of the kaolin powder was determined by spectroscopic techniques, as Xray fluorescence for metals and by atomic absorption for alkaline earth metals.

Phase identification was performed by XRD analysis (Philips X'Pert X-ray) diffractometer) with $\mathrm{Cu}$ Ka radiation $\left(\lambda=1.5406 \mathrm{~A}^{\circ}\right)$, and the crystalline phases were identified by reference to the International Center for Diffraction Data cards.

Fourier transforms infrared (FTIR) spectra by the $\mathrm{KBr}$ method using an IR spectrometer [Perkin-Elmer spectrum BX]. The spectra were collected for each measurement over the spectral range 600-4000 $\mathrm{cm}^{-1}$ with a resolution of $4 \mathrm{~cm}^{-1}$.

Thermogravimetric analysis (TG) and differential thermal analysis (DTA) were carried out from ambient temperature to $1300^{\circ} \mathrm{C}$ at a rate of $10^{\circ} \mathrm{C} \mathrm{min}^{-1}$ under air, using a setaram SETSYS Evolution 1750 .

The particle size distributions of kaolin $(\mathrm{K})$ were determined by the Dynamic Laser Scattering (DLS) technique using water as dispersing medium (Mastersizer 2000, Malvern Instruments).

\section{Supports elaboration}

The different steps for preparing ceramic materials is the choice of the nature and particle size of the ceramic powder, the choice of organics additions, the optimal volume of water, the aging time paste, shaping by extrusion, and the time of drying and sintering. The preparation of the porous membranes involved the formulation of a plastic and homogeneous paste that contained the clay ceramic powder mixed with organic additive and water.

The optimal formulation of the ceramic precursor paste was carried out in an empirical way. The selected composition of powders used for the plastic paste preparation was $90 \mathrm{wt} . \%$ Kaolin (K) and $10 \mathrm{wt} . \%$ Starch as a plasticizer. To dos this, a quantity of $540 \mathrm{~g}$ of kaolin and 60 $\mathrm{g}$ of starch powders were uniformly dry mixed using a rotary mixer at a speed of $65 \mathrm{rpm}$ for $10 \mathrm{~min}$. The powder mixture was aged with a progressive addition of water $(300 \mathrm{ml})$. Water content was adapted according to the type of clay material used in the formulation. As a result, more homogeneity in the final substrate structure was acquired. Before the extrusion phase, an aging stage of the aqueous suspension is necessary to obtain a good homogeneity and to favor the formation of porosities. This step is required to prepare a paste with rheological properties allowing the shaping by extrusion. To this end, the excess of liquid was eliminated and the obtained paste was kept in a closed plastic bag for $24 \mathrm{~h}$ under high humidity environment to avoid premature drying and ensure a homogenous distribution of water and organic additives. After aging, the paste was extruded into the tubular specimens trough an extruder and then the wet pieces are set on stems at room temperature during $24 \mathrm{~h}$ to ensure a homogenous drying and to avoid twisting and blending.

Finally, a thermal treatment was carried out in a programmable furnace at different final temperatures. The Type 30400 Automatic and Programmable furnaces are general laboratory and heat treating furnaces. Two steps have been determined. Subsequently, the membrane was heated up to $400^{\circ} \mathrm{C}$ for $2 \mathrm{~h}$ at a heating rate of $2^{\circ} \mathrm{C} /$ $\mathrm{min}$ in order to eliminate the organic additive used as pore-forming agent. In a second step, the support was sintered at a temperature

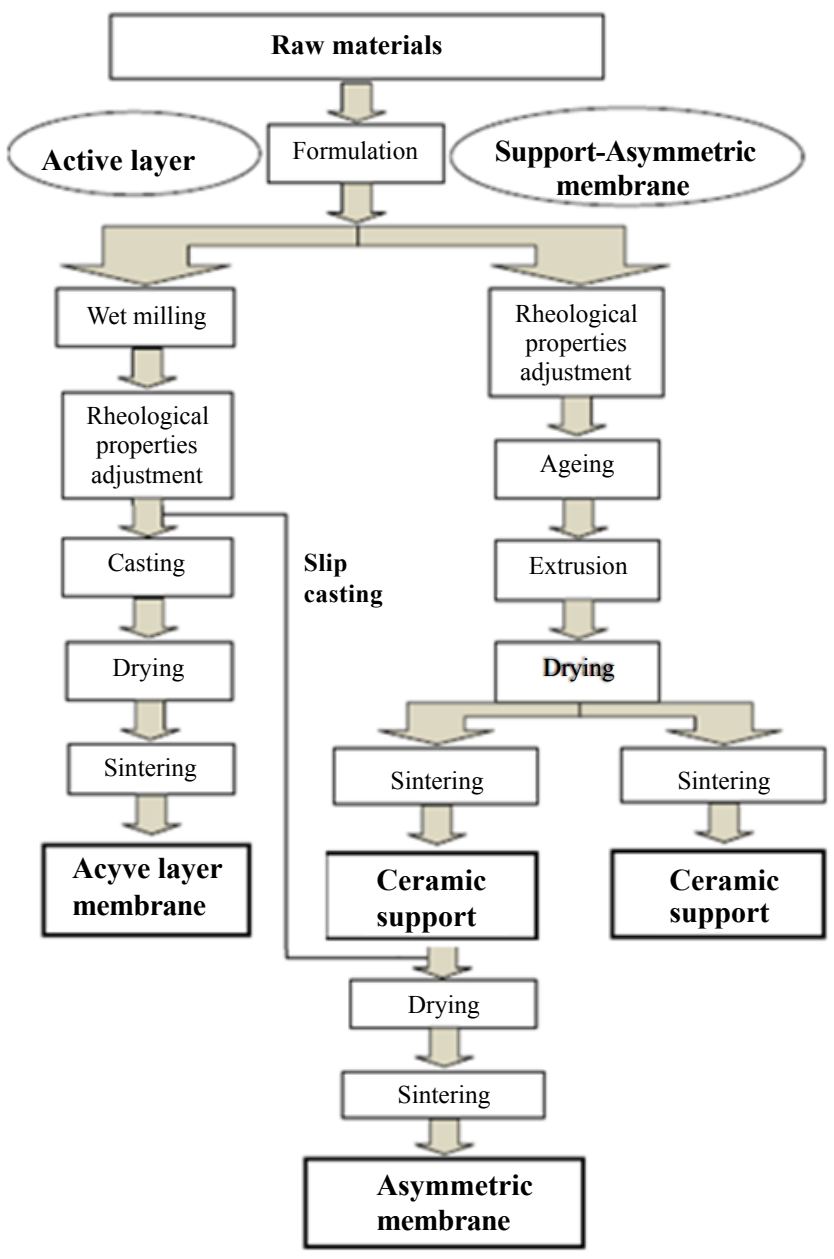

Figure 1: Schematic representation of support, active layer and asymmetric ceramic membrane preparation. 
ranging from 1100 to $1250^{\circ} \mathrm{C}$ with a ramping rate of $5^{\circ} \mathrm{C} \mathrm{min}^{-1}$ in order to avoid the formation of cracks during sintering of the samples. The final temperature was kept constant for $1 \mathrm{~h}$. After that, the consolidated support was allowed to cool until the environmental temperature was reached.

The temperature-time schedule not only affects the pore diameters and porous volume of the final product but also allows obtaining the final morphology and mechanical strength. Tubular supports were elaborated with external/internal diameter of $16 / 11 \mathrm{~mm}$ and the length of $150 \mathrm{~mm}$.

\section{Supports characterization}

The evolution of densification and surface quality of the supports sintered at different temperatures were determined by scanning electron microscopy.

Porosity and pore size distribution were measured by mercury porosimetry. This technique relies on the penetration of mercury into a membrane's pores under pressure [34-36,50,51]. The intrusion volume is recorded as a function of the applied pressure and then the pore size was determined.

The mechanical resistance tests were performed using the three points bending method (LLOYD Instrument) to control the resistance of the membranes fired at different temperatures.

The corrosion tests were carried out using aqueous solutions of nitric acid $(\mathrm{pH}=2.5)$ and sodium hydroxide $(\mathrm{pH}=12.5)$ at 45 and $80^{\circ} \mathrm{C}$, respectively. All the samples were ultrasonically rinsed in distilled water, dried at $110^{\circ} \mathrm{C}$ and stored in a dryer. The degree of corrosion was characterized by the percentage of the weight loss.

\section{Ultrafiltration membrane elaboration}

To decrease the probability of cracking or fissures during the sintering process of the membrane, in the preparation of the active layer the same raw materials of the support were used.

The active ultrafiltration layer from kaolin was prepared by a slip casting process on kaolin support from a mixture of the inorganic powder and a $12 \mathrm{wt} . \%$ aqueous solution of polyvinylique alcohol (PVA) (Rhodoviol 25/140 (Prolabo)), which is used as binder and plasticizer. The slip casting process $[42,52]$ was applied to coat the support tube to elaborate ultrafiltration membrane as described in Figure 1.

In the first step, a stable suspension or slip has to be obtained by putting in suspension the mineral powder in water. Then, $12 \mathrm{wt} \%$ aqueous solution of PVA was mixed to the preceding suspension. Desagglomeration of the mineral powder and homogenization of the coating formulation was ensured by mechanical stirring using an ordinary magnetic stirrer at its maximum speed. The coating formulation was poured inside the support for a few minutes at room temperature while the tube was closed at one end. A layer is then formed on the inner side of the porous tube due to capillary suction. Afterwards, the excess was drained out. Drying was realized at room temperature for 24 hours. The sintering temperature was fixed at $650^{\circ} \mathrm{C}$ for 3 hours. A heating temperature at $250^{\circ} \mathrm{C}$ for 2 hours is necessary in order to eliminate completely the PVA, present in great quantity in the slip [3]. Relatively slow temperature rate $\left(2^{\circ} \mathrm{C} / \mathrm{min}\right)$ was needed in order to avoid the formation of cracks on the layer.

\section{Composition and characterization of the slip}

Different coating formulations B.n differing by PVA concentration $(1<\mathrm{n}<3)$ and kaolin powder $(4<\mathrm{n}<8)$ were used to determine the optimal composition of the final layer.

At the first time, the kaolin powder quantity was kept at $4 \%$ when the PVA aqueous solution percentage was varied and then, at the second time, the PVA aqueous solution percentage was fixed to $40 \%$ when the kaolin powder percentage was varied (Tables 1 and 2).

The viscosity is an important parameter to determine the slip optimal composition. It was measured just before slip casting by using an Antoon Paar rheometer model MCR301.

\section{Filtration pilot}

The laboratory pilot used for the filtration experiments was equipped with a cross-flow filtration system implementing tubular ceramic membrane of $15 \mathrm{~cm}$ length. The tubular membrane takes place in a stainless steel carter. The transmembrane pressure (TMP) can reach 8 bars wich corresponds to the ultrafiltration range. It was controlled by an adjustable valve on the retentate side. Temperature was kept at $25^{\circ} \mathrm{C}$ by a thermal exchange system. The membrane was conditioned by immersion in pure deionized water for a minimum of $24 \mathrm{~h}$ before filtration tests. The determination of the water membrane permeability was performed with distilled water.

\section{Effluent characterization}

Wastewater samples were taken from the effluents produced by a sea-product freezing factory located in Sfax, Tunisia. The dark colour in this effluent was due to the presence of sepia ink (containing melanin) as suspension particles which have a size range between 56 and 161 $\mathrm{nm}[31]$.

A large number of analyses were conducted on each sample and the following parameters were measured: turbidity, Chemical Oxygen Demand (COD), temperature, $\mathrm{pH}$ and conductivity. The COD values of raw effluents from the production process ranged between 2000 and $3000 \mathrm{mgL}^{-1}$ with an average concentration of $2615 \mathrm{mgL}^{-1}$. The turbidity measured for the raw effluent presents a very high value which is in the range of 335 NTU (Table 3 ).

The techniques used to analyze collected samples of feed, retentate and permeate are reported below:

- Turbidity: Using a HACH «2100 N Turbidimeter» turbidimeter.

\begin{tabular}{|c|c|c|}
\hline Coating formulation & \% of PVA $^{\mathbf{a}}$ & \% of water \\
\hline B. 1 & 20 & 76 \\
\hline B. 2 & 30 & 66 \\
\hline B. 3 & 40 & 56 \\
\hline
\end{tabular}

a: the percentage of PVA here is relatif to the quantity of the 12-wt $\%$ PVA aqueous solution added to the powder-water dispertion.

Table 1: Composition of coating formulation prepared with different percentage of PVA.

\begin{tabular}{|c|c|c|}
\hline Coating formulation & \% of kaolin & $\begin{array}{c}\text { \% of water/PVA } \\
\text { aqueous solutions }\end{array}$ \\
\hline B.4 & 2 & 94 \\
\hline B.5 & 4 & 92 \\
\hline B.6 & 6 & 90 \\
\hline B.7 & 8 & 88 \\
\hline B. & 10 & 86 \\
\hline b: mixture of 12 wt \% PVA aqueous solution and water \\
\hline
\end{tabular}

Table 2: Composition of coating formulation prepared with varying percentage of kaolin. 


\begin{tabular}{|c|c|c|c|}
\hline $\begin{array}{c}\text { Turbidity } \\
\text { (NTU) }\end{array}$ & $\begin{array}{c}\text { COD } \\
\left(\mathbf{m g} . \mathbf{L}^{-1}\right)\end{array}$ & $\begin{array}{c}\text { Conductivity } \\
\left(\mathbf{m S}^{-\mathbf{c m}^{-1}}\right)\end{array}$ & $\mathbf{p H}$ \\
\hline 335 & 2615 & 204 & 7 \\
\hline
\end{tabular}

Table 3: Turbidity, COD, conductivity and $\mathrm{pH}$ of raw effluents.

- Dissolved organic carbon: Using a «REHROTEST TRS 200 NF T 90-101» COD Analyser.

- Conductivity: Using a «Consort K 911» conductimeter.

\section{Results and Discussion}

\section{Powder characterization}

The chemical composition of kaolin is given in Table 4, where the main impurities are $\mathrm{CaO}, \mathrm{K} 2 \mathrm{O}, \mathrm{TiO}_{2}$ and $\mathrm{Fe}_{2} \mathrm{O}_{3}$. It reveals that the major components were silica $\left(\mathrm{SiO}_{2}: 47.85 \%\right)$ and aluminium oxide $\left(\mathrm{Al}_{2} \mathrm{O}_{3}: 37.60 \%\right)$.

Phase identification is of great importance before any membrane manufacturing. For example, Figure 2 presents the XRD patterns of the raw kaolin. It can be seen that kaolinite $(\mathrm{K})$ was the major mineral component with a small amount of quartz (Q) and illite (I) impurities. No other components were observed, because the impurities are in so tiny quantity (Table 4) and most of them are probably incorporated into the crystal structure of kaolinite.

The results of FTIR spectroscopy of the starting clay (Figure 3) show the kaolin characteristic bands: Si-O (at around 993, 1024, and $1112 \mathrm{~cm}^{-1}$ ), Si-O-Al (at around 525, 750, and $795 \mathrm{~cm}^{-1}$ ), Al-OH (at around $910 \mathrm{~cm}^{-1}$ ) and $\mathrm{OH}$ (at around 3684, 3668, 3651, and $3618 \mathrm{~cm}^{-1}$ ) $[48,49,53]$.

The particle size distribution of kaolin was determined by the Dynamic Laser Scattering (DLS) technique, and the results shown in Figure 4 . This method gave an average particle size in the order of $4 \mu \mathrm{m}$.

A total weight loss is observed by TGA to be about $15 \%$ of kaolin (Figure 5). In fact, the weight loss consists of two distinct stages: The first one is considered as a slight weight loss between room temperature and $150^{\circ} \mathrm{C}$, because of the dehydration of the clay. The second mass loss detected between about 400 and $700^{\circ} \mathrm{C}$ is mainly due to the phenomenon of dehydroxylation of kaolinite confirmed by DTA which shows an endothermic peak at $560^{\circ} \mathrm{C}$ leading to the transformation of kaolinite to metakaolinite. A third stage, wich is characterized by an exothermic reaction appeared at about $975^{\circ} \mathrm{C}$ without any weight loss. The exothermic peak corresponds to the metakaolin-mullite transformation [54].

\section{Supports characterization}

For the development of high-quality supports, the following properties are of major importance: pore size distribution, porosity, surface texture, mechanical properties and chemical stability.

Supports morphology: Figure 6 illustrates SEM pictures for the supports sintered at the four different temperatures considered in this work. The optimal sintering temperature was determined by comparing the texture of the different obtained samples.

The ceramic substrates sintered at lower temperature $\left(1100^{\circ} \mathrm{C}\right)$ show highly porous structure. Below $1100^{\circ} \mathrm{C}$, we detect the presence of intergranular contacts which are large enough to ensure the ceramics cohesion (beginning of sintering). We observe that the formation of grain boundaries is achieved within a narrow temperature range of $1150^{\circ} \mathrm{C}-1200^{\circ} \mathrm{C}$. The aspect of the surface is homogeneous and does not present any macro defect (cracks, etc.). Beyond $1250^{\circ} \mathrm{C}$, the densification process (shrinkage) dominates and a relatively open structure is still observed.

The morphology as well as the microstructure of optimal support fired at $1150^{\circ} \mathrm{C}$ is shown in Figure 6 for the cross section and the surface views. A smooth inner surface is observed which will allow the deposit of a homogeneous membrane layer.

Open porosity and pore size distribution for supports: The evolution of the average pore diameter and the porosity with the temperature of sintering reveals that the porosity decreases from 49 to $35 \%$ between $1100^{\circ} \mathrm{C}$ and $1250^{\circ} \mathrm{C}$, while the pore diameter increased from 0.81 to $1.4 \mu \mathrm{m}$ (Figure 7). The beginning of the material densification occurred when the temperature increases [25,33,36,37,41,55].

At $1150^{\circ} \mathrm{C}$, the characteristics of the support are an average pore diameter of $1 \mu \mathrm{m}$ and a porosity of $44 \%$. Consider Figure 8 which presents a Single (mono) Modal of pore size distribution or

\begin{tabular}{|c|c|c|c|c|c|c|c|c|}
\hline & $\mathrm{SiO}_{2}$ & $\mathrm{Al}_{2} \mathrm{O}_{3}$ & $\mathrm{Fe}_{2} \mathrm{O}_{3}$ & $\mathbf{M g O}$ & $\mathrm{K}_{2} \mathrm{O}$ & $\mathbf{C a O}$ & $\mathrm{TiO}_{2}$ & LOI $^{*}$ \\
\hline $\begin{array}{c}\text { Kaolin } \\
(\%)\end{array}$ & 47.85 & 37.60 & 0.83 & 0.17 & 0.97 & 0.57 & 0.74 & 11.27 \\
\hline
\end{tabular}

* LOI: Loss on Ignition at $1000^{\circ}$

Table 4: Chemical composition of the used kaolin (wt \%).

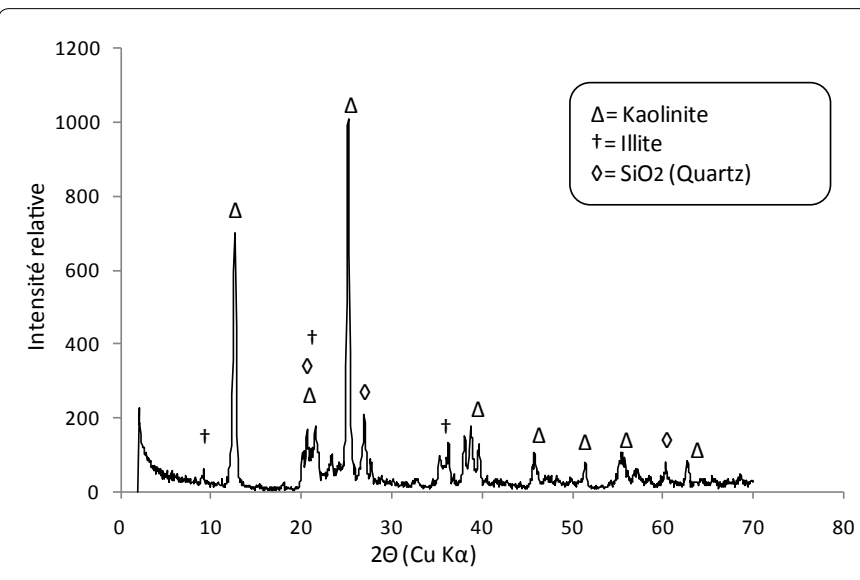

Figure 2: XRD pattern of the pure kaolin.

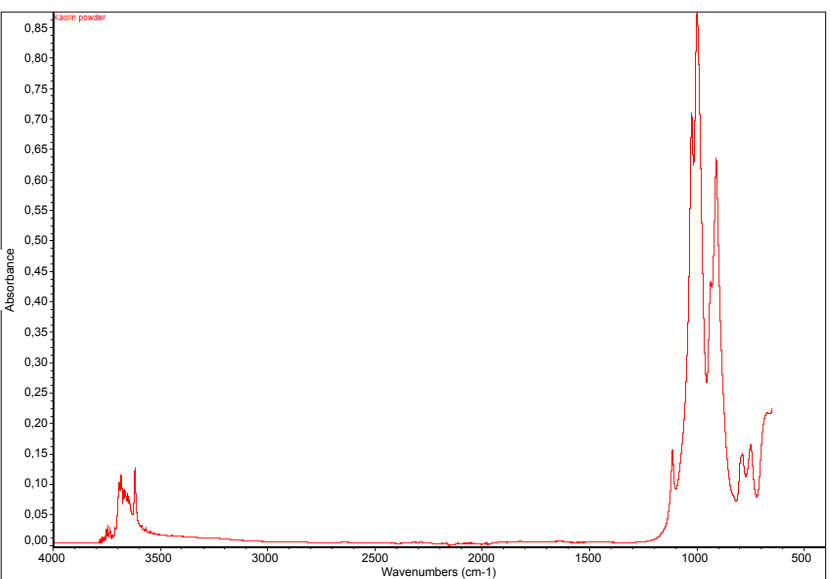

Figure 3: FTIR spectrum of kaolin. 


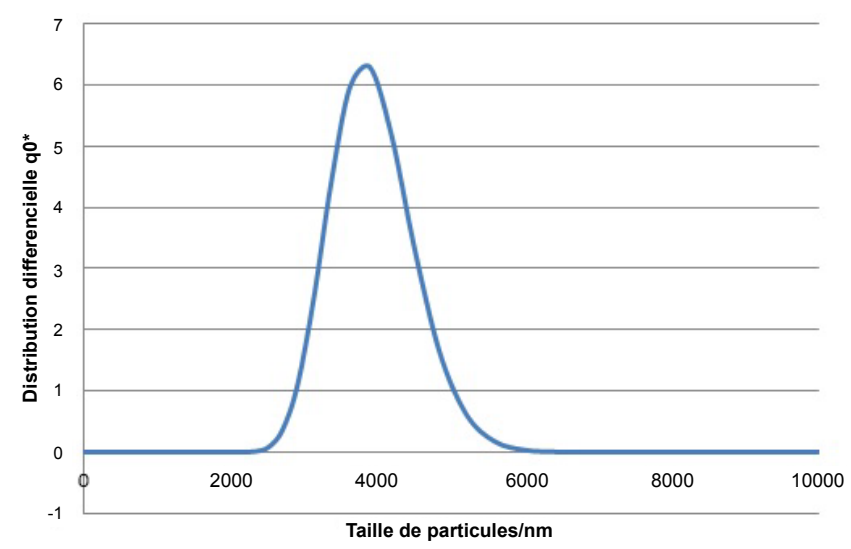

Figure 4: Particle size distribution of kaolin.

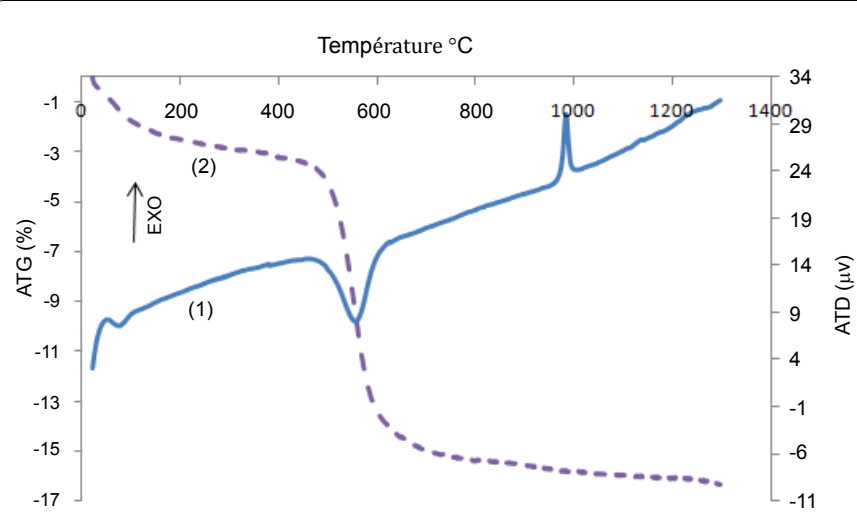

Figure 5: TGA-DTA data of the kaolin powder.
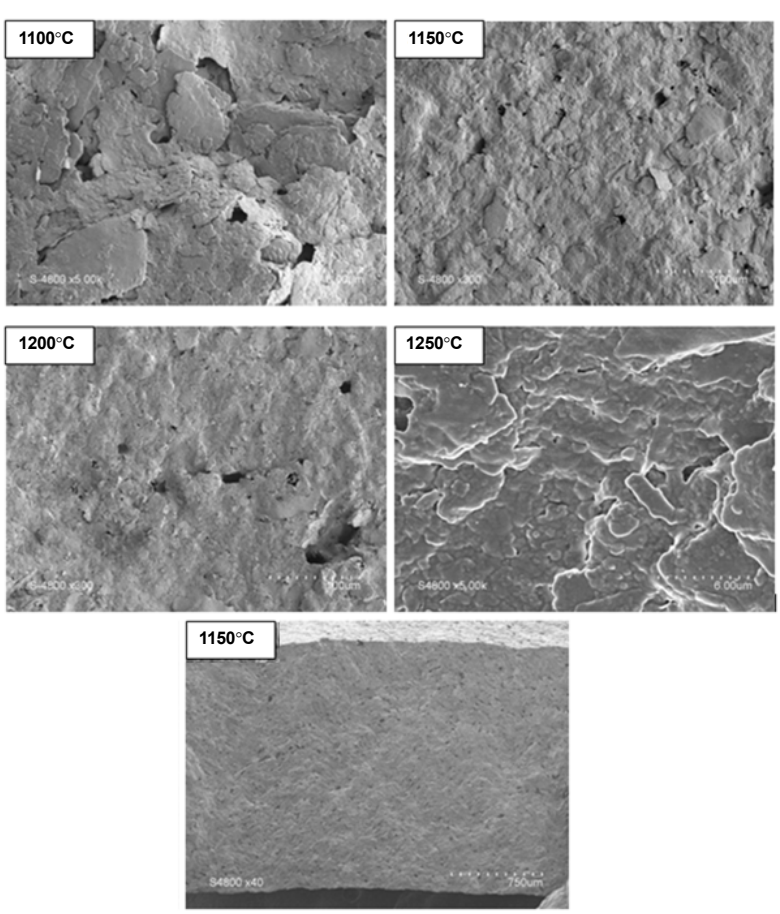

Figure 6: SEM pictures of the elaborated supports fired at various sintering temperature.
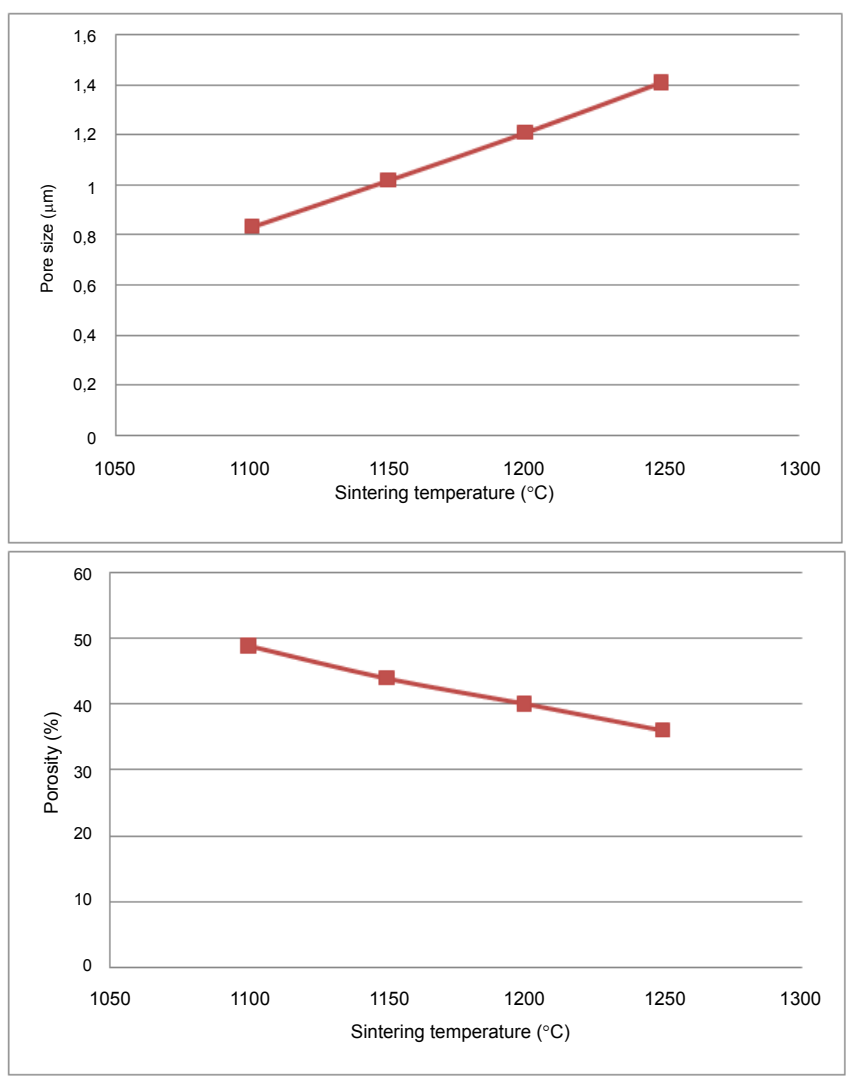

Figure 7: Effect of sintering temperature on average pore size and porosity of supports.

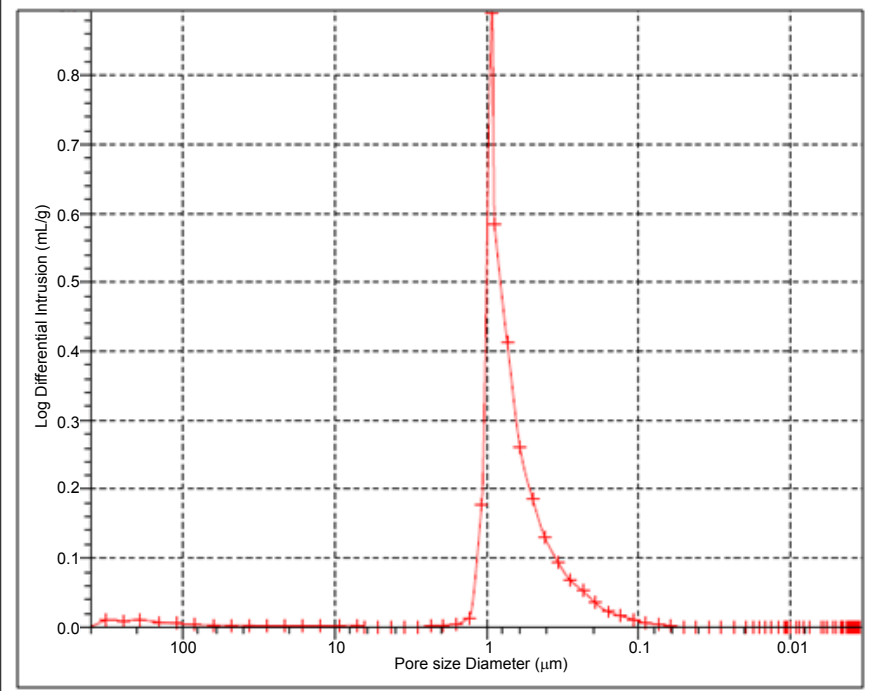

Figure 8: Pore size distribution of support sintered at $1150^{\circ} \mathrm{C}$.

homogenous pore distribution. This is necessary for a good integrity of the membrane.

Mechanical resistance: Figure 9 shows the variation of flexural strength with sintering. In accordance with the SEM pictures and the porosity values, the increase of the sintering temperature is accompanied with a densification phenomenon and consequently an 


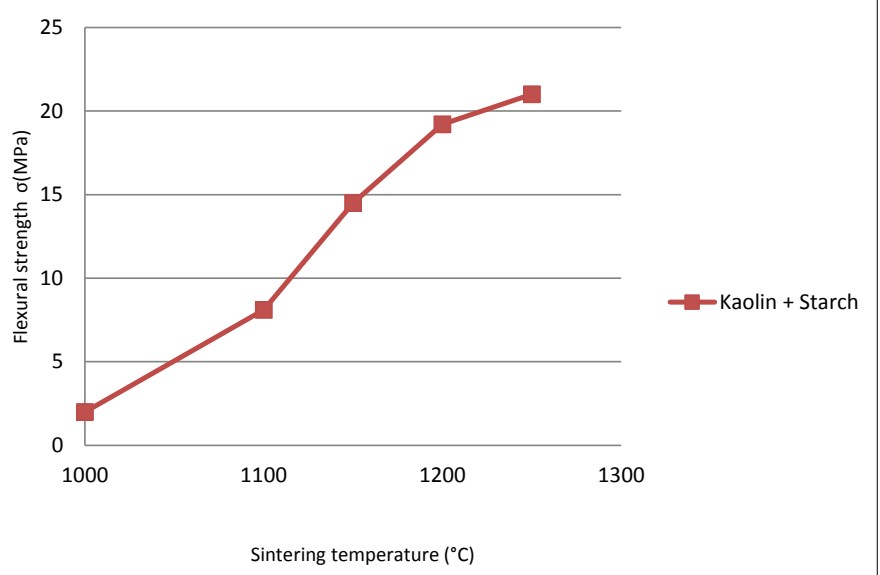

Figure 9: Variation of Flexural strength with sintering temperature of the supports.

increase in the tensile strength from $3 \mathrm{MPa}$ at $1000^{\circ} \mathrm{C}$ to $21 \mathrm{MPa}$ at $1250^{\circ} \mathrm{C}$.

Chemical corrosion: The weight loss due to the corrosion of acids and alkali is shown in Figure 10. It can be seen that the membrane shows a better acid corrosion resistance, since its mass loss is much lower than those of supports after alkali corrosion. Therefore, the observed results in weight loss during corrosion tests suggest that the prepared support possesses a good chemical corrosion resistance and it is suitable for applications involving acidic and basic media.

Choice of the support: Finally the best condition to prepare the support are established for a firing temperature of $1150^{\circ} \mathrm{C}$, at this condition the average pore diameter is $1 \mu \mathrm{m}$ and the porosity is $44 \%$. Moreover this support presents good mechanical resistance having a tensile strength of $15 \mathrm{MPa}$, and also good chemical properties towards the acid and basic solutions. Thus, membrane support sintered at $1150^{\circ} \mathrm{C}$ for 1 hour has been selected as substrates for filtration tests.

\section{Rheological characterization of the suspension}

For a good adhesion on the macroporous support, viscosity must be sufficient to facilitate the coating and to prevent that the support does not absorb solvent too quickly. Many parameters were studied in order to optimise the slip composition (percentage mass in PVA, percentage mass in kaolin, temperature, etc.).

Influence of temperature: The influence of the temperature on the suspension viscosity was studied using different concentrations of PVA (20\%, 30\% and $40 \%)$ and kaolin (2\%-10\%). The mineral study used for coating was tested at varying temperatures ranging from 25 to $80^{\circ} \mathrm{C}$. As expected, a rise of temperature leads to a decrease of the suspension viscosity (Figures 11 and 12) according to an exponential relationship whose expression is given by Dufauda [56]:

$$
\eta=A \cdot e^{E a / R t}
$$

Where $\mathrm{A}$ is the pre-exponential factor, $\mathrm{Ea}$ is the activation energy for viscous flow, $\mathrm{R}$ is the gas constant $\left(8.314 \mathrm{~J} \mathrm{~mol}^{-1} \mathrm{~K}^{-1}\right)$, and $\mathrm{T}$ is the absolute temperature. The logarithm of the viscosity plotted against the inverse of temperature bits well aspect Arrhenius relation.

Figures 11a and 12a show that the viscosity increases considerably with increasing the concentration of kaolin powder and PVA but decreases with the increase of the temperature in the range $25-80^{\circ} \mathrm{C}$. The influence of temperature on the composition and viscosity can be described using Arrhenius Law. The determination of the activation energy Ea shows a pronounced sensitivity of the viscosity to temperature changes $[57,58]$.

Figures $11 \mathrm{~b}$ and $12 \mathrm{~b}$ show an evolution accorded to Arrhenius law for the different prepared suspensions with an increase of the logarithmic viscosity with the percentage of loading of PVA and kaolin in the temperature range between $20^{\circ} \mathrm{C}$ and $70^{\circ} \mathrm{C}$. A straight line was obtained using Arrhenius model which fitted reasonably well with the experimental data and gave high R2 equal to 0.99 with $99 \%$ confidence level.

Table 5 lists the corresponding flow activation energy $\Delta \mathrm{Ea}$ and the

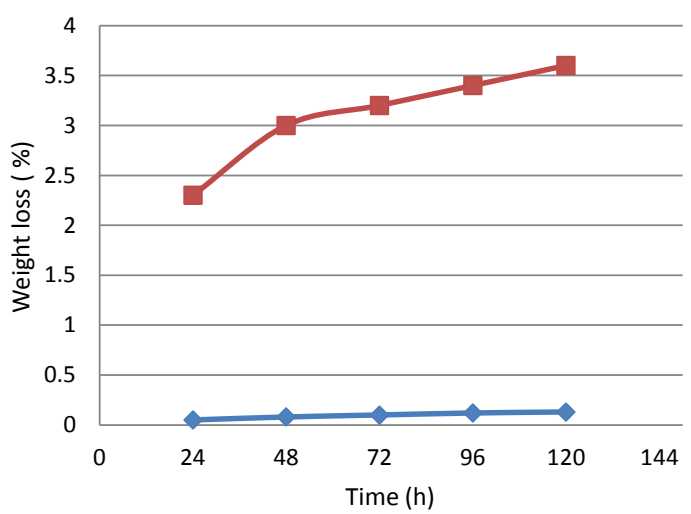

Figure 10: Weight loss of membranes in nitric acid $\left(45^{\circ} \mathrm{C}\right)$ and soda solutions $\left(80^{\circ} \mathrm{C}\right)$ as a function of time.

(a)

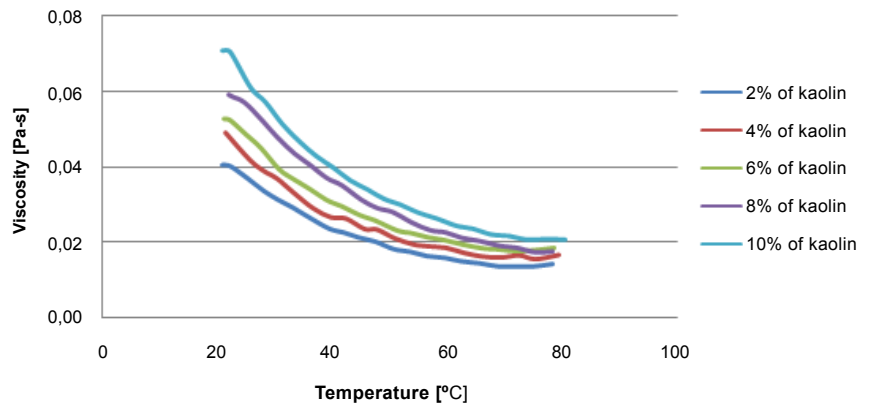

(b)

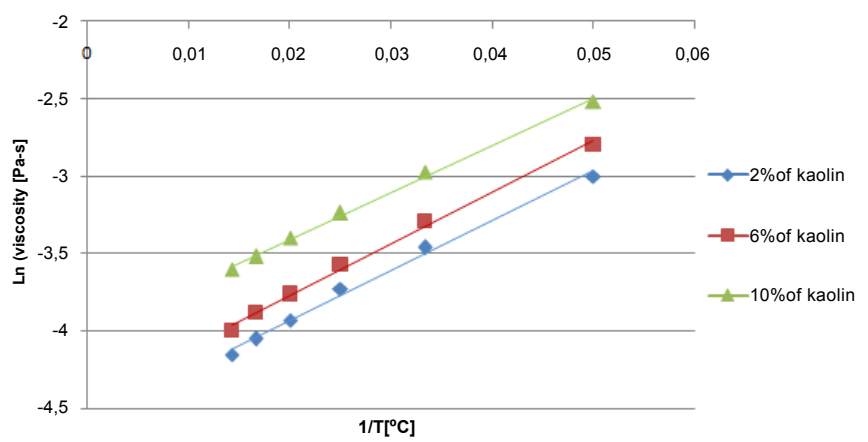

Figure 11: Evolution of viscosity with the temperature for different kaolin concentrations. 
(a)

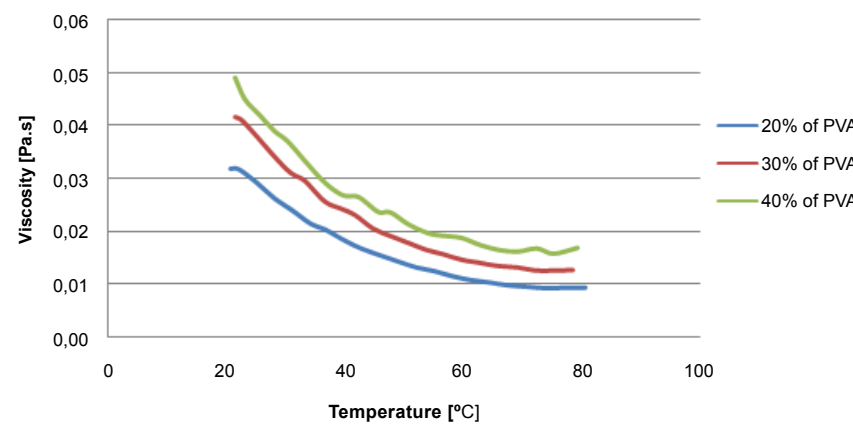

(b)

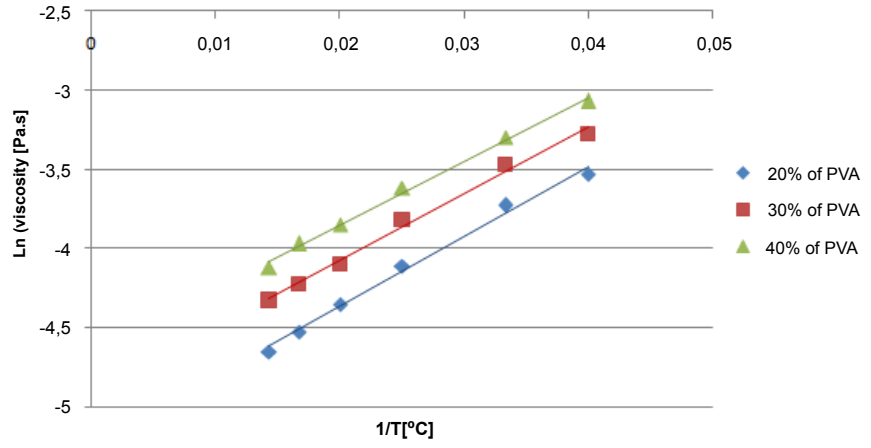

Figure 12: Evolution of viscosity with the temperature for different PVA concentrations.

related fit stability index R2 for different suspensions. With increasing concentration of kaolin powder and PVA, a pronounced increase of the flow activation energy can be observed. Such results are in agreement with the values given in the literature $[57,58]$ and are due to the increasing interaction of the particles with the polymer.

In slip casting process, capillary suction is the driving force that causes the layer deposition on the inner side of the support. Then, to obtain a good and homogenous layer, the suspension does not have to be very viscous nor fluid. The effect of PVA and mineral powder percentages on the viscosity of the suspension is due to the fact that increasing concentration would have a direct effect on the fluid internal shear stress while the temperature effect is obviously due to a weakening temperature of inter-particle and inter-molecular adhesion forces [59].

The PVA and the mineral powder percentage, have a direct influence on the suspension viscosity. This influence is more important for low temperatures. A temperature of $25^{\circ} \mathrm{C}$ to $35^{\circ} \mathrm{C}$ will be retained since the layer deposition process is technically possible only at low temperatures. The PVA percentage has the stronger effect on the viscosity, so, it is of interest to study its effect on the rheological behavior of the suspension.

Influence of PVA percentage: Figure 13 shows that the viscosity of the suspension increases slightly depending on the stirring period. However, the increase of PVA percentage leads to a considerable increase of the viscosity. Such rheological behavior is explained by the different types of interactions susceptible to be established between PVA used as Binder and kaolin particles which depend on the concentration of both of them [57]. In conclusion, a stirring time of 90 minutes is a medium duration that can be used when preparing the suspension to be used.
From Figure 14, it can be noticed that dynamic viscosity decreases slightly according to the speed of shearing, but this variation remains insufficient for the determination of the nature of the behavior of such suspension. For identifying the rheological behavior, the variation of the shear stress $(\tau)$ according to the speed of shearing (D) was determined.

Figure 15 shows that the behavior of dip solution (B.1, B.2 and B.3) is of Newtonian type. The shear rate increases according to the speed of shearing $\mathrm{D}$. These samples show a Newtonian behavior generated by an increase in inter-particle interactions due to increasing the concentration of PVA and formation of complex flocculated structures. Suspension with a PVA percentage comprised between 20 and $40 \%$ can be apparently used to deposit the layer.

Finally, to obtain a suspension with a viscosity of 0.042 Pa.s and having a Newtonian behavior at room temperature of 25 to $30^{\circ} \mathrm{C}$, the suspension should have a composition of $4 \%$ of kaolin and $40 \%$ of PVA and stirred for 90 minutes.

\begin{tabular}{|l|l|l|l|l|l|l|}
\hline suspension & $\begin{array}{l}\mathbf{2} \% \text { of } \\
\text { kaolin }^{\mathbf{a}}\end{array}$ & $\begin{array}{l}\mathbf{6 \%} \text { of } \\
\text { kaolin }^{\mathbf{a}}\end{array}$ & $\begin{array}{l}\mathbf{1 0 \%} \text { of } \\
\text { kaolin }^{\mathbf{a}}\end{array}$ & $\begin{array}{l}\mathbf{2 0 \%} \text { of } \\
\text { PVA }^{\mathbf{b}}\end{array}$ & $\begin{array}{l}\mathbf{3 0 \%} \text { of } \\
\text { PVA }^{\mathbf{b}}\end{array}$ & $\begin{array}{l}\mathbf{4 0 \%} \text { of } \\
\text { PVA }^{\mathbf{b}}\end{array}$ \\
\hline $\begin{array}{l}\boldsymbol{\Delta} \mathrm{Ea}(\mathrm{KJ} \mathrm{J} \\
\mathbf{m o l})\end{array}$ & 17.44 & 19.43 & 20.28 & 16.85 & 17.50 & 18.64 \\
\hline $\mathbf{R}^{2}$ & 0.993 & 0.995 & 0.997 & 0.992 & 0.992 & 0.995 \\
\hline
\end{tabular}

a: PVA aqueous solution was fixed at $40 \%$

b: Kaolin powder $\%$ was fixed at $4 \%$

Table 5: Estimation of the flow activation energy Ea for kaolin-PVA.

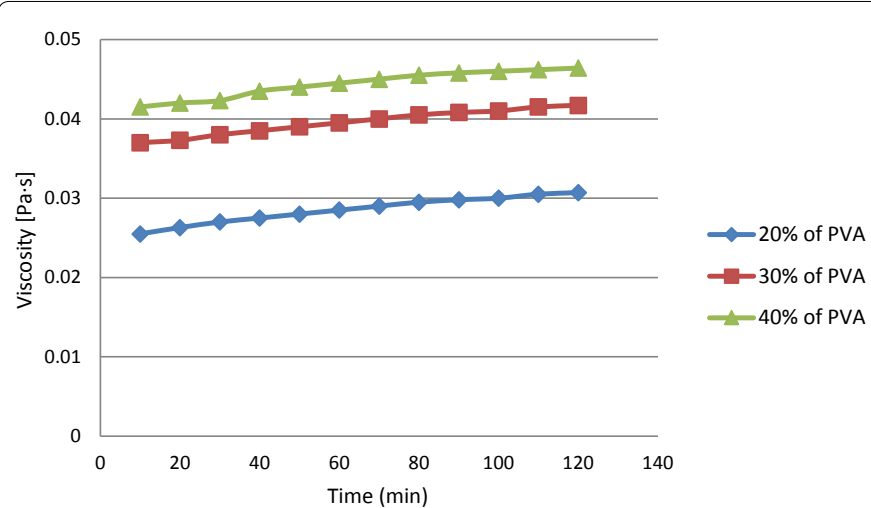

Figure 13: Evolution of the viscosity with the time of stirring for different PVA concentrations.

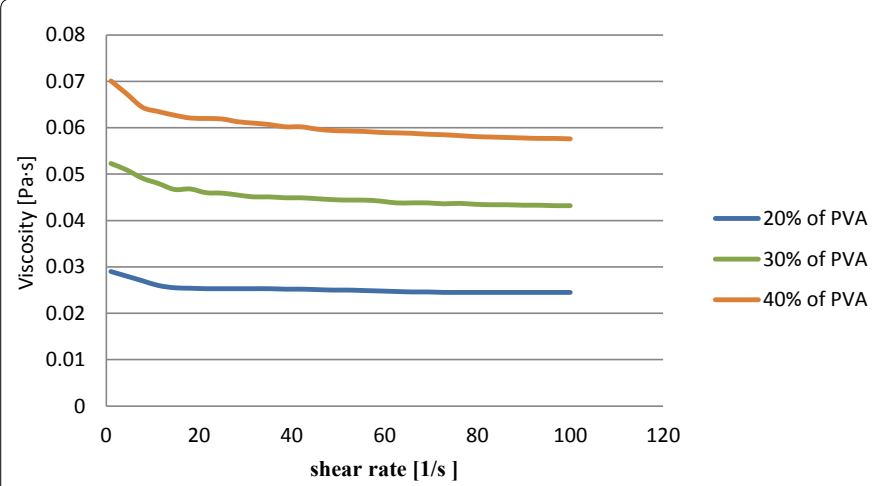

Figure 14: Evolution of the viscosity with the percentage of $\mathrm{PVA}\left(\mathrm{T}=25^{\circ} \mathrm{C}\right.$ and $4 \%$ of kaolin) 
Citation: Rekik SB, Bouaziz J, Deratani A, Baklouti S (2016) Development of an Asymmetric Ultrafiltration Membrane from Naturally Occurring Kaolin Clays: Application for the Cuttlefish Effluents Treatment. J Membra Sci Technol 6: 159. doi:10.4172/2155-9589.1000159

Page 8 of 12

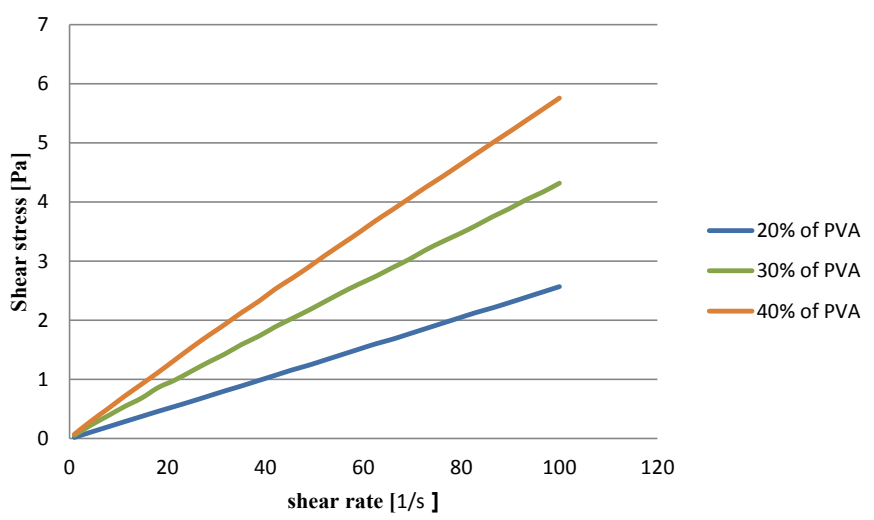

Figure 15: Evolution of the shear stress with the percentage of $\mathrm{PVA}\left(\mathrm{T}=25^{\circ} \mathrm{C}\right.$, kaolin: 4\%).

\section{Membrane characterization}

Scanning electron microscopy (SEM): Influence of PVA percentage: Three layers were cast on clay tubular supports using three different suspension compositions (B.1, B.2 and B.3). The same casting time was used during the slip casting operation (6 min). The sintering conditions, previously mentioned, were respected.

Figure 16, which shows SEM pictures for surface and cross-section of the obtained layers, give information about the thickness and texture. According to the SEM analysis, it can be noticed at first, that there is a good adhesion between the layer and the clay support. No detachment is observed on the different cross section photographs.

The optimal composition for coating suspension is obtained by using $40 \%$ PVA (B.3). This composition enables us to achieve a thickness of $8 \mu \mathrm{m}$ for ultrafiltration and homogeneous surface free from defects (such as cracks, etc.). On the other hand, the composition corresponding to $20 \%$ of PVA (B.1) enables us to obtain a thickness of $3 \mu \mathrm{m}$. So, B. 3 composition was retained for the preparation of an ultrafiltration membrane.

Influence of deposition time: The deposition of the slip B.3 on the clay support was performed by slip casting using a deposition time between 2 and $20 \mathrm{~min}$. Different ultrafiltration membranes with different layers thickness (between 3 and $30 \mu \mathrm{m}$ ) were prepared. SEM (scanning electron microscopy) images of the resulting membranes are shown in Figure 16.

B. 3 composition was retained for the preparation of an ultrafiltration membrane. The casting time was fixed to $6 \mathrm{~min}$.

Mercury porosimetry: The average pore size of the optimized membrane was determined by mercury porosimetry. The pore diameter measured was centered near $11 \mathrm{~nm}$ (Figure 17), which confirms that an ultrafiltration layer was achieved.

Determination of membrane permeability: The membrane was initially characterized by the determination of water permeability. It can be seen that the pure water flux increases linearly with increasing the applied pressure (Figure 18). The membrane permeability was found to be equal to $78 \mathrm{l} / \mathrm{h} \cdot \mathrm{m}^{2}$.bar.

\section{Application to the treatment of the cuttlefish effluents}

The elaborated ultrafiltration membranes have been applied to the cuttlefish effluents treatment. Figure 19 gives the variation of permeate flux with transmembrane pressure. Permeate flux increased linearly with transmembrane pressure until 6 bar and then became pressure independent. This behavior can be explained by the formation of a concentrated polarization layer. Beyond 6 bar, the flux value is about 64 l/h.m².

The variation of the permeate flux with time at different transmembrane pressures (TMP) from 2 to 6 bar and a temperature of $25^{\circ} \mathrm{C}$, as shown in Figure 20. Permeate flux decreases with the time and stabilizes after the first $20 \mathrm{~min}$ whatever the pressure value. This behavior can be attributed to the fouling due to the interaction between membrane material and the waste water solution. It is important to notice that fouling is not very important since the flux decline did not exceed $15 \%$ for the different pressures used. This is a specific behavior of
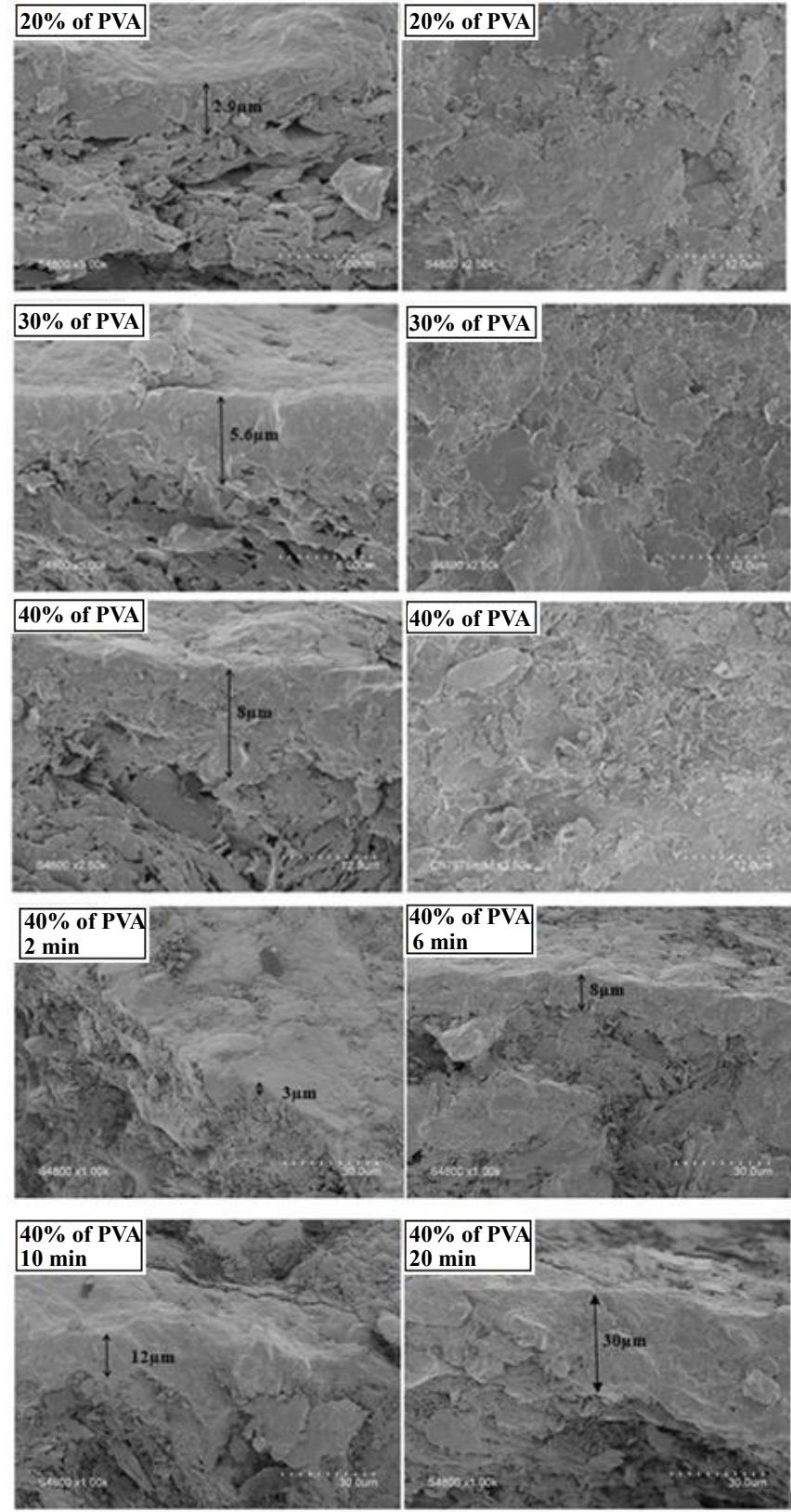

Figure 16: SEM micrographs (cross section and surface) of active laye obtained with different slip compositions and deposition time. 


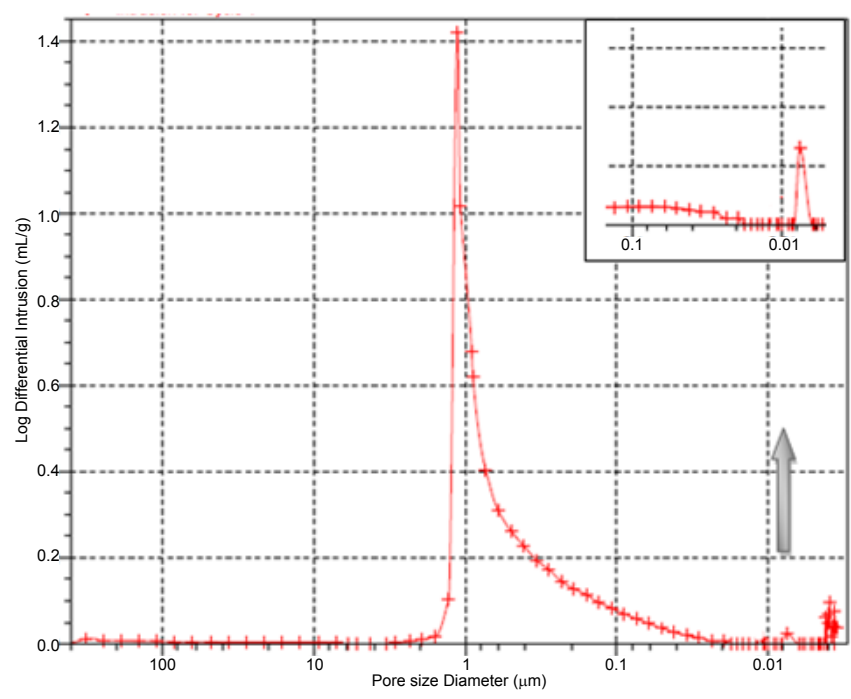

Figure 17: Pore diameters distribution of the kaolin ultrafiltration layer.

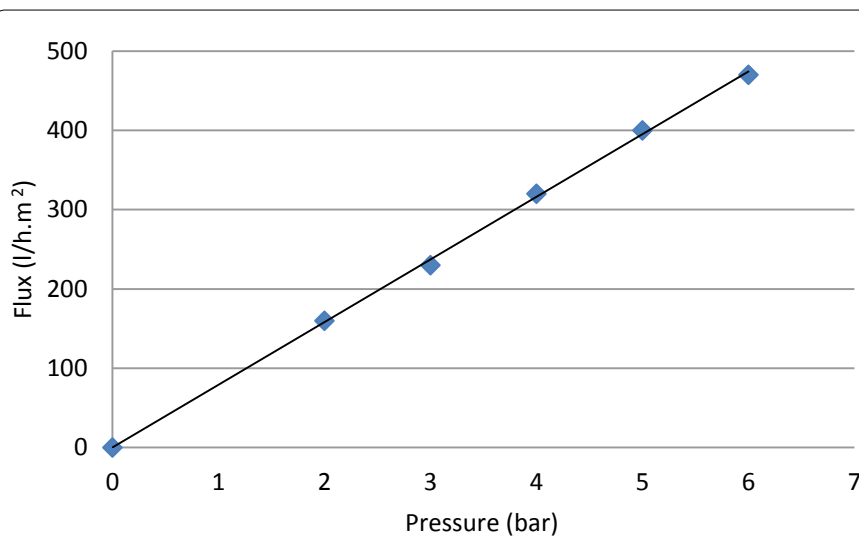

Figure 18: Water flux permeability versus working pressure.

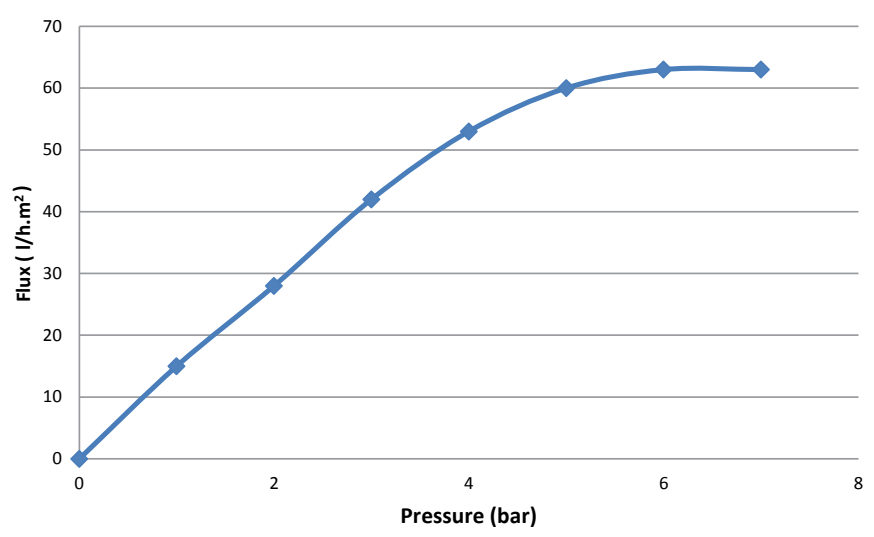

Figure 19: Variation of the permeate flux with pressure.

the UF membrane compared to MF membrane that showed generally an important decrease of flux due to pores blocking by retained particles $[3,42]$.

Ultrafiltration performances: Table 6 gives the main physicochemical parameters analyzed for permeate obtained by UF kaolin membrane. These analyses show variability in the turbidity and COD values. The turbidity of the ultrafiltrated effluent was $0.62,0.95$ and $1.36 \mathrm{NTU}$ respectively for 2,4 and 6 bar. The values of COD (from 350 to $530 \mathrm{mg} \mathrm{L}^{-1}$ with TMP from 2 to 6 bar). The conductivity values were usually in the range of $140-148 \mathrm{~ms}^{-\mathrm{cm}^{-1}}$.

Percentage reduction of turbidity and COD as a function of TMP has been shown in Figure 21. Both the turbidity and COD reduction have been found to increase with decrease in TMP, which could be attributed due to the higher rejection at lower TMP. As pressure increases, more melanin permeates through the membrane leaving most of solutes to through the pores of the membrane by increasing transmembrane pressure and subsequently decreased rejection.

Turbidity of permeate was found to get reduced by $99.8 \%$ when UF was carried out at a TMP of 2 bar, whereas, COD was reduced by only $87 \%$. However, the conductivity in the permeate decreases slightly and is pressure independent. In fact, at all the TMP level, turbidity

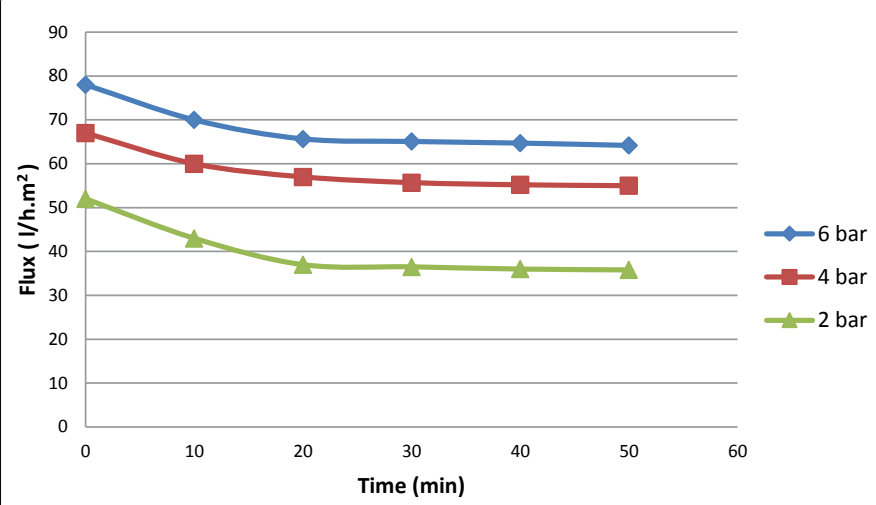

Figure 20: Variation of the permeate flux with time of filtration.

\begin{tabular}{|c|c|c|c|c|}
\hline & $\begin{array}{c}\text { Pressure } \\
\text { (bar) }\end{array}$ & $\begin{array}{c}\text { Turbidity } \\
\text { (NTU) }\end{array}$ & $\begin{array}{c}\text { COD } \\
(\mathbf{m g . L})\end{array}$ & $\begin{array}{c}\text { Conductivity } \\
\text { (mS.cm-1 }\end{array}$ \\
\hline Raw effluents & & 335 & 2615 & 204 \\
\hline \multirow{3}{*}{ Filtrate } & 2 & 0,62 & 350 & 140 \\
\cline { 2 - 5 } & 4 & 0,95 & 460 & 146 \\
\cline { 2 - 5 } & 6 & 1,36 & 530 & 148 \\
\hline
\end{tabular}

Table 6: Characteristics of the effluent before and after filtration on kaolin membranes.

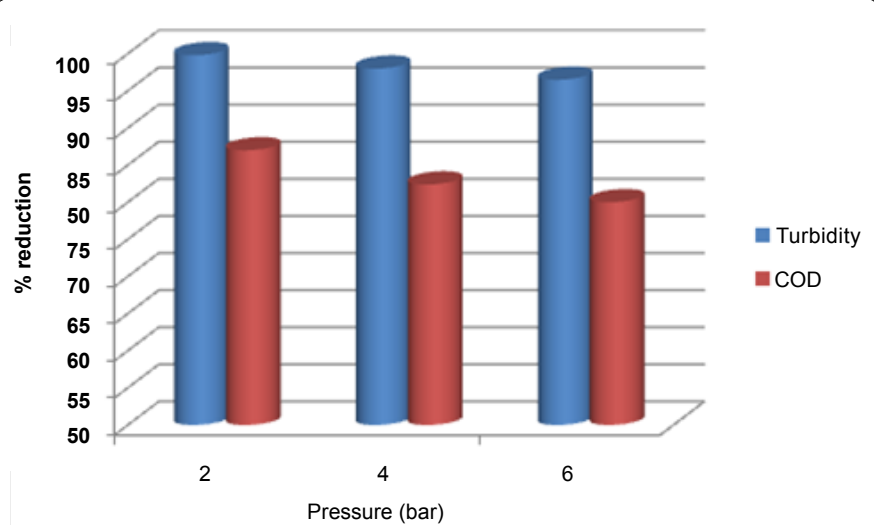

Figure 21: Effect of transmembrane pressures in ultrafiltration on turbidity and COD reduction. 
reductions were found to be more than the corresponding COD reduction on percentage basis. As the COD is caused by the presence of low molecular inorganic chemicals also, which might pass through the membrane, may give less (\%COD).

Evaluations of resistances: The volume flux in a pressure driven membrane process depends on the hydraulic resistance of the used membrane and the pressure drop over the membrane. This is generally expressed by the following formula:

$$
\mathrm{J}_{\mathrm{w}}=\Delta \mathrm{P} / \eta_{\mathrm{w}} \mathrm{R}_{\mathrm{m}} \mathrm{J}_{\mathrm{w}}
$$

where, $\mathrm{R}_{\mathrm{m}}$ is the intrinsic hydraulic resistance of the membrane and $\eta_{w}$ is the viscosity of water.

The permeate flux $\left(\mathrm{J}_{\mathrm{s}}\right)$ after filtration of the solution can be expressed by the resistance-in-series model.

$$
J_{s}=\Delta P / \eta_{s} R_{t} J_{s}
$$

in which $\eta_{\mathrm{s}}$ is the permeate viscosity and $\mathrm{R}_{\mathrm{t}}$ is the total resistance that can be defined as:

$$
\mathrm{R}_{\mathrm{t}}=\mathrm{R}_{\mathrm{m}}+\mathrm{R}_{\mathrm{c}}
$$

where, $R_{c}$ is the total resistance fouling.

Experimentally, the intrinsic membrane resistance $\mathrm{R}_{\mathrm{m}}$ was calculated by measuring the pure water flux $J_{w}$ and viscosity $\eta w$.

Total resistance $\mathrm{R}_{\mathrm{t}}$ was estimated from the solution flow rates under operating conditions using Equation (2):

$$
\mathrm{R}_{\mathrm{t}}=\Delta \mathrm{P} / \eta_{\mathrm{s}} \mathrm{J}_{\mathrm{s}}
$$

The intrinsic membrane resistance and the total fouling resistance deduced from these Equations for kaolin membrane are presented in Table 7. The major part of the total resistance was due to fouling $\left(\left(R_{p}+R_{f}\right) / R_{t}\right)$ for different working pressure. Intrinsic membrane resistance $\left(R_{m} / R_{t}\right)$ represented a small portion of the total resistance.

\section{Membrane regeneration}

After each experiment, the membrane must be regenerated. The efficiency of the using protocol is verified by the measurement of water flux. The regeneration of the membrane was carried out by firstly, the membrane was exposed to an acid-basic washing sequence (Table 8), and secondly, by leaving the membrane in distilled water. The used protocol appears sufficient because we obtained the value of the initial permeability of the membranes (Figure 22).

\section{Conclusion}

In this work, a comprehensive study on the fabrication and characterization of an asymmetric ultrafiltration membrane from naturally occurring- kaolin clays were performed. Ceramic supports have been obtained by extrusion using kaolin powder with corn starch as poreforming agent. It has been concluded that the supports

\begin{tabular}{|c|c|c|c|c|c|}
\hline $\begin{array}{l}\text { Pressure } \\
\text { (bar) }\end{array}$ & $\begin{array}{c}R_{t}\left(10^{12}\right) \\
\left(m^{-1}\right)\end{array}$ & $\begin{array}{c}R_{m}\left(10^{12}\right) \\
\left(m^{-1}\right)\end{array}$ & $\begin{array}{c}R_{c}\left(10^{12}\right) \\
\left(m^{-1}\right)\end{array}$ & $R_{m} / R_{t}(\%)$ & $\mathrm{R}_{\mathrm{c}} / \mathrm{Rt}(\%)$ \\
\hline 2 & 20.11 & 4.61 & 15.5 & 22.92 & 77.08 \\
\hline 4 & 26.18 & 4.61 & 21.57 & 17.6 & 82.4 \\
\hline 6 & 33.75 & 4.61 & 29.14 & 13.66 & 86.34 \\
\hline
\end{tabular}
sintered at $1150^{\circ} \mathrm{C}$ is the optimum supports allowed for depositing the membrane layers. The mechanical and structural properties of the supports are satisfying in terms of porosity and pore diameter.

Table 7: Resistance values for kaolin membrane.

\begin{tabular}{|c|c|c|c|c|c|}
\hline Sequence & Agent & Concentration & $\mathbf{T}\left({ }^{\circ} \mathbf{C}\right)$ & $\begin{array}{c}\text { Pressure } \\
(\mathbf{B a r})\end{array}$ & $\begin{array}{c}\text { Time } \\
(\mathbf{m i n})\end{array}$ \\
\hline Rinsing then evacuation & water & & $\mathrm{RT}$ & 2 & \\
\hline Basic washing & $\mathrm{NaOH}$ & $5-10 \mathrm{~g} \mathrm{~L}^{-1}$ & $60-65$ & 2 & 30 \\
\hline Rinsing until neutrality & water & & $\mathrm{RT}$ & 2 & \\
\hline $\begin{array}{c}\text { Acidic washing } \\
\text { Rinsing until neutrality }\end{array}$ & $\mathrm{HNO}_{3}$ & $5 \mathrm{ml} \mathrm{L}^{-1}$ & $40-50$ & 2 & 30 \\
\hline water & & RT & 2 & \\
\hline${ }^{*} \mathrm{RT}:$ Room Temperature & & & & \\
\hline
\end{tabular}

Table 8: Acido-basic washing sequence.

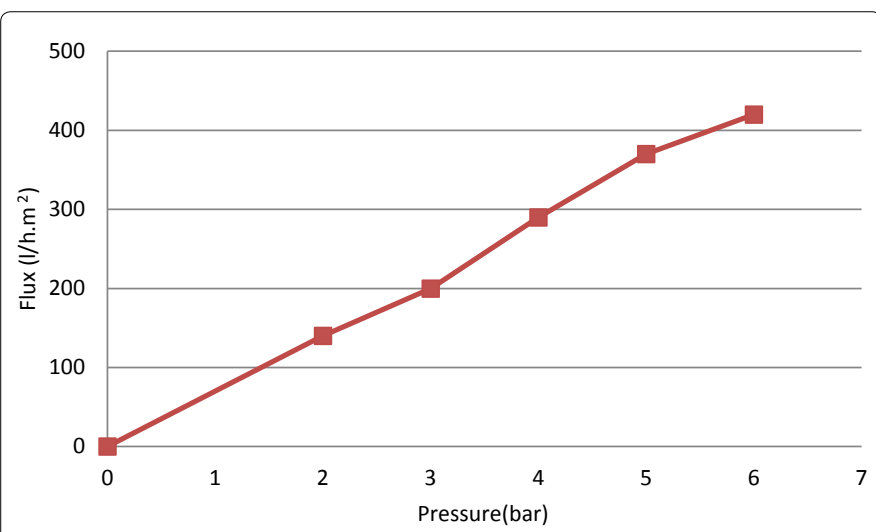

Figure 22: Variation of the permeate flux with pressure for Kaolin membrane after regeneration.

The UF layer, deposited on the supports, was obtained by the slipcasting technique. The composition of the slip was optimized using a rheological study. An excellent link between the support and the ultrafiltration layer was obtained. The thickness of the ultrafiltration layer is about $9 \mu \mathrm{m}$; it can be controlled by the percentage of the PVA powder added in the slip suspension and the duration of the deposition time. The obtained membrane has an average pore size diameter of about $11 \mathrm{~nm}$ and a water permeability of $78 \mathrm{l} / \mathrm{h} \cdot \mathrm{m}^{2}$.bar. This result may allow the novel membrane to be used in water treatment in the ultrafiltration range.

The application of this membrane to the washing cuttlefish effluent treatment exhibited an acceptable stabilized permeate flux of almost $64 \mathrm{l} / \mathrm{h} \cdot \mathrm{m}^{2}$ at 2 bar and $25^{\circ} \mathrm{C}$ with a very important decrease of different pollutants in terms of turbidity (99\%) and COD (87\%). These membranes can also be used as a support for nanofiltration layer.

\section{Acknowledgments}

Authors would like to thank IEM (European Institute of Membranes), UMRCNRS 5635/ENSCM Montpellier/University Montpellier 2, for their help to carry out the analysis.

\section{References}

1. Xu L, Li W, Lu S, Wang Z, Zhu Q, et al. (2002) Treating dyeing waste water by ceramic membrane in cross flow microfiltration. Desalination 149: 199-203.

2. Ebrahimi M, Ashaghi KS, Engel L, Willershausen D, Mund P, et al. (2009) Characterization and application of different ceramic membranes for the oilfield produced water treatment. Desalination 245: 533-540.

3. Masmoudi S, Amar RB, Larbot A, El Feki A, Salah AB, et al. (2005) Elaboration of inorganic microfiltration membranes with hydroxyapatite applied to the treatment of waste water from sea product industry. J Membr Sci 247: 1-9.

4. Khemakhem S, Amar RB, Hassen RB, Larbot A, Medhioub M, et al. (2004) New ceramic membranes for tangential waste-water filtration. Desalination 167: 19-22.

5. Kumar SM, Madhu GM, Roy S (2007) Fouling behaviour, regeneration options 
Citation: Rekik SB, Bouaziz J, Deratani A, Baklouti S (2016) Development of an Asymmetric Ultrafiltration Membrane from Naturally Occurring Kaolin Clays: Application for the Cuttlefish Effluents Treatment. J Membra Sci Technol 6: 159. doi:10.4172/2155-9589.1000159

and on-line control of biomass-based power plant effluents using micro porous ceramic membranes. Sep Purif Technol 57: 25-36

6. Nandi BK, Das B, Uppaluri R, Purkait MK (2009) Microfiltration of mosambi juice using low cost ceramic membrane. J Food Eng 95: 597-605.

7. Wang BJ, Wei TC, Yu ZR (2005) Effect of operating temperature on component distribution of West Indian cherry juice in a microfiltration system. LWT 38 : 683-689.

8. Zulewska J, Newbold M, Barbano DM (2009) Efficiency of serum protein removal from skim milk with ceramic and polymeric membranes at $50^{\circ} \mathrm{C}$. J Dairy Sci 92: 1361-1377.

9. Espina VS, Jaffrin MY, Frappart M, Ding LH (2008) Separation of case in micelles from whey proteins by high shear microfiltration of skim milk using rotating ceramic membranes and organic membranes in a rotating disk module. J Membr Sci 325: 872-879.

10. Saboya LV, Maubois JL (2000) Current developments of microfiltration technology in the dairy industry. Lait 80 : 541-553.

11. Pouliot $Y$ (2008) Membrane processes in dairy technology - from a simple idea to worldwide panacea. Int Dairy J 18: 735-740.

12. Kao PM, Huang SC, Chang YC, Liu YC (2007) Development of continuous chitin as e production process in a membrane bioreactor by Paenibacillus $\mathrm{sp}$. CHE-N1. Process Bio chem 42: 606-611.

13. Larbot A (2003) Fundamentals on inorganic membranes: present and new developments. Pol J Chem Technol 6: 8-13.

14. Li K (2007) Ceramic Membranes for Separation and Reaction, John Wiley \& Sons, Ltd, West Sussex, England.

15. Monash P, Pugazhenthi G (2011) Effect of TiO2 addition on the fabrication of ceramic membrane supports: a study on the separation of oil droplets and bovine serum albumin (BSA) from its solution. Desalination 279: 104-114.

16. Han JH, Oh E, Bae B, Song IH (2013) The effect of kaolin addition on the characteristics of a sintered diatomite composite support layer for potential microfiltration applications. Ceram Int 39: 8955-8962.

17. Han JH, Oh E, Bae B, Song IH (2013) The fabrication and characterization of sintered diatomite for potential microfiltration for applications. Ceram Int 39 : 7641-7648.

18. Schillo MC, Park LS, Chiu WV, Verweij H (2010) Rapid thermal processing of inorganic membranes. J Membr Sci 362: 127-133.

19. Zhu J, Fan Y, Xu N (2010) Preparation and characterization of alumina membranes on capillary supports: effect of film-coating on crack-free membrane preparation Chin. J Chem Eng 3: 377-383.

20. Qin W, Peng C, Lv M, Wu J (2014) Preparation and properties of high-purity porous alumina support at low sintering temperature. Ceram Int 40: 1374113746.

21. Li G, Qi H, Fan Y, Xu N (2009) Toughening macroporous alumina membrane supports with YSZ powders. Ceram Int 35: 1641-1646.

22. Liu C, Wang L, Ren W, Rong Z, Wang X (2007) Synthesis and characterization of a mesoporous silica (MCM-48) membrane on a large-pore $\alpha-\mathrm{Al} 2 \mathrm{O} 3$ ceramic tube. Microporous Mesoporous Mater 106: 35-39.

23. Wang YH, Tian TF, Liu XQ, Meng GY (2006) Titania membrane preparation with chemical stability for very hash environments applications. J Membr Sci 280: 261-269.

24. Yoshino Y, Suzuki T, Nair BN, Taguchi H, Itoh N (2005) Development of tubular substrates, silica based membranes and membrane modules for hydrogen separation at high temperature. J Membr Sci 267: 8-17.

25. Masmoudi S, Larbot A, Feki H, Amar RB (2007) Elaboration and characterization of apatite based mineral supports for microfiltration and ultrafiltration membranes. Ceram Int 33: 337-344.

26. Saffaj N, Persin M, Younsi SA, Albizane A, Cretin M, et al. (2006) Elaboration and characterization of microfiltration and ultrafiltration membranes deposited on raw support prepared from natural Moroccan clay: application to filtration of solution containing dyes and salts. Appl Clay Sci 31: 110-119.

27. Palacio L, Bouzerdi Y, Ouammou M, Albizane A, Bennazha J, et al. (2009) Ceramic membranes from Moroccan natural clay and phosphate for industrial water treatment. Desalination 245: 501-507.
28. Loukili H, Younssi SA, Albizane A, Bennazha J, Persin M, et al. (2008) The rejection of anionic dyes solutions using an ultrafiltration ceramic membrane. Phys Chem News 41: 98-1011.

29. Jana S, Purkait MK, Mohanty K (2010) Preparation and characterization of low-cost ceramic microfiltration membranes for the removal of chromate from aqueous solutions. Appl Clay Sci 47: 317-324

30. Ayadi S, Jedidi I, Rivallin M, Gillot F, Lacour S, et al. (2013) Elaboration and characterization of new conductive porous graphite membranes for electrochemical advanced oxidation processes. J Membr Sci 446: 42-49.

31. Khemakhem M, Khemakhem S, Ayedi S, Amar RB (2011) Study of ceramic ultrafiltration membrane support based on phosphate industry subproduct: application for the cuttlefish conditioning effluents treatment. Ceram Int 37 : 3617-3625.

32. Khemakhem M, Khemakhem S, Ayedi S, Cretin M, Amar RB (2015) Development of an asymmetric ultrafiltration membrane based on phosphates industry sub-products. Ceram Int 49: 10343-10348.

33. Bouzerara F, Harabi A, Achour S, Labrot A (2006) Porous ceramic supports for membranes prepared from kaolin and doloma mixtures. J Eur Ceram Soc 26: $1663-1671$

34. Boudaira B, Harabi A, Bouzerara F, Condom S (2009) Preparation and characterization of microfiltration membranes and their supports using kaolin (DD2) and CaCO3. Desalin Water Treat 9: 142-148.

35. Bouzerara F, Harabi A, Condom S (2009) Porous ceramic membranes prepared from kaolin. Desalin Water Treat 12: 415-419.

36. Harabi A, Guechi A, Condom S (2012) Production of supports and filtration membranes from Algerian kaolin and limestone. Procedia Eng 33: 220-224.

37. Zenikheri F, Boudaira B, Bouzerara F, Guechi A, Foughali L (2014) A new and economic approach to fabricate resistant porous membrane supports using kaolin and CaCO3. J Eur Ceram Soc 34: 1329-1340.

38. Tewari PK, Singh RK, Batra VS, Balakrishnan M (2010) Membrane bioreactor (MBR) for waste water treatment: filtration performance evaluation of low cos polymeric and ceramic membranes. Sep Pur Technol 71: 200-204.

39. Dong Y, Liu X, Ma Q, Meng G (2006) Preparation of cordierite-based porous ceramic micro-filtration membranes using waste fly ash as the main raw materials. J Membr Sci 285: 173-181.

40. Cao J, Dong X, Li L, Dong Y, Hampshire S (2014) Recycling of waste fly ash for production of porous mullite ceramic membrane supports with increased porosity. J Eur Ceram Soc 34: 3181-3194

41. Jedidi I, Khemakhem S, Larbot A, Amar RB (2009) Elaboration and characterisation of fly ash based mineral supports for microfiltration and ultrafiltration membranes. Ceram Int 35: 2747-2753.

42. Jedidi I, Saïdi S, Khemakhem S, Larbot A, Elloumi-Ammar N, et al. (2009) Elaboration of new ceramic microfiltration membranes from mineral coal fly ash applied to waste water treatment. J Hazard Mater 172: 152-158.

43. Hanemann T (2006) Viscosity change of unsaturated polyester-alumina composites using polyethylene glycol alkyl ether based dispersants, Composites: Part A. Applied Science and Manufacturing 37: 2155-2163.

44. Tsetsekou A, Agrafiotis C, Milias A (2001) Optimization of the rheologica properties of alumina slurries for ceramic processing applications Part I: Slipcasting. J Eur Cer Soc 21: 363-373.

45. Masmoudi S, Larbot A, Feki HE, Amar RB (2006) Elaboration and properties of new ceramic microfiltration membranes from natural and synthesised apatite. Desalination 190: 89-103.

46. Zhang Y, Yokogawa Y, Feng X, Tao Y, Li Y (2010) Preparation and properties of bimodal porous apatite ceramics through slip casting using different hydroxyapatite powders. Ceram Int 36: 107-113.

47. Chaari K, Bouaziz J (2005) Rheological behavior of organic suspensions of fluorapatite. J Colloid Interface Sci 285: 469-475.

48. Sahnoun RD, Bouaziz J (2012) Sintering characteristics of kaolin in the presence of phosphoric acid binder. Ceram Int 38: 1-7.

49. Boulmokh A, Berredjem Y, Guerfi K, Gheid A (2014) Kaolin from Djebe Debbagh Mine Guelma Algeria. J Appl Sci 2: 435-440.

50. Harrabi A, Bouzerara F, Condom S (2009) Preparation and characterization 
Citation: Rekik SB, Bouaziz J, Deratani A, Baklouti S (2016) Development of an Asymmetric Ultrafiltration Membrane from Naturally Occurring Kaolin Clays: Application for the Cuttlefish Effluents Treatment. J Membra Sci Technol 6: 159. doi:10.4172/2155-9589.1000159

of tubular membrane supports using centrifugal casting. Desal Water Treat 6 : 222-226.

51. Bouzerara F, Harrabi A, Ghouil B, Medjemem N, Boudaira B, et al. (2012) Synthesis and characterization of multilayer ceramic membranes. Proc Eng 33: $278-284$

52. Tahri N, Jedidi I, Cerneaux S, Cretin M, Amar RB (2013) Development of an asymmetric carbon microfiltration membrane: application to the treatment of industrial textile wastewater. Sep Purif Technol 118: 179-187.

53. Majouli A, Younssi SA, Tahiri S, Albizane A, Loukili H (2011) Characterization of flat membrane support elaborated from local Moroccan Perlite. Desalination 277: 61-66.

54. Issaoui M, Bouaziz J (2015) Elaboration of membrane ceramic supports using aluminium powder, Desalin. Water Treat 53: 1037-1041.
55. Fakhfakh S, Baklouti S, Bouaziz J (2013) Elaboration and characterisation of low cost ceramic support membrane. Adv appl ceram 109: 31-38.

56. Dufauda O, Marchal P, Corbel S (2002) Rheological properties of PZT suspensions for stereolithography. J Eur Ceram Soc 22: 2081-2092.

57. Hanemann T (2008) Influence of particle properties on the viscosity of polymeralumina composites. Ceram Int 34: 2099-2105.

58. Nasri H, Khemakhem S, Amar RB (2014) Physico-Chemical Study of Coating Formulation Based on Natural Apatite for the Elaboration of Microfiltration Membrane. Periodica Polytechnica 58: 171-178.

59. Nguyen AT, Desgranges F, Roy G, Galanis N, Mare T, et al. (2007) Temperature and particle-size dependent viscosity data for water-based nanofluids - Hysteresis phenomenon. International Journal of Heat and Fluid Flow 28: 1492-1506. 